\title{
FINDING AND EVALUATING JOURNALS
}

FGCU Library
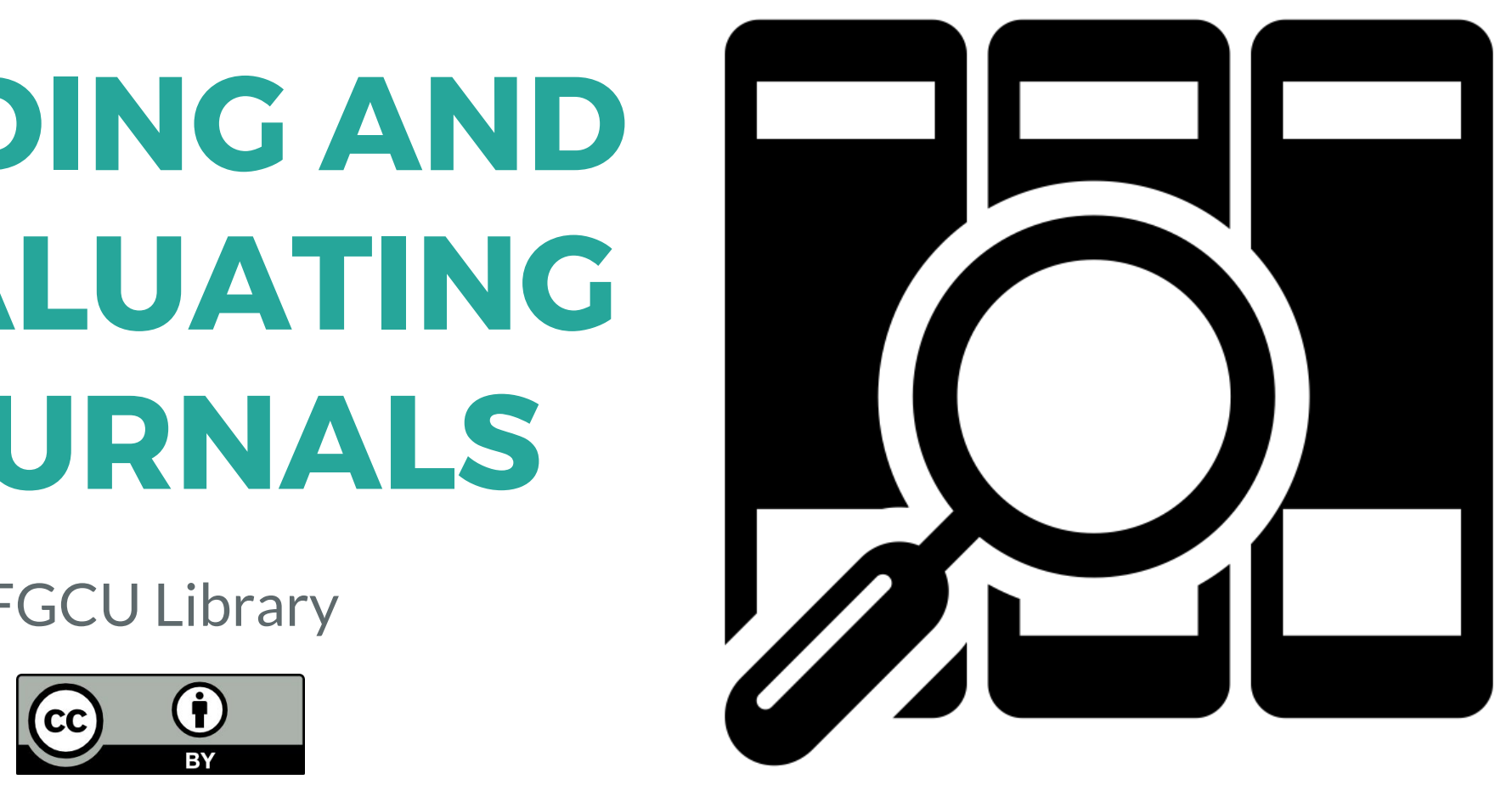


\title{
Today's Topics
}

\section{What journal should I publish in?}

\author{
Is this journal trustworthy?
}

What is Open Access? 


\section{Goals}

You'll gain a greater understanding of journals and Open Access
You'll trust yourself to

$+\quad$ evaluate journals or know who to go to for help 


\section{How do you find journals?}




\section{Top (obvious) Tips}

- Look at where your peers are publishing

- What journals are you reading?

- Talk to your colleagues! 


\section{Resources}

- Cofactor Journal Selector Tool

- Journal Citation Reports

- Elsevier Journal Finder

- Edanz Journal Selector

- Ulrich's Web

- Directory of Open Access Journals

- Your subject librarian!

- There are some subject specific journals lists

- Faculty Scholarship libguide: fgcu.libguides.com/faculty 


\section{Evaluating Journals: Think. Check. Submit.}

Think

Can I trust this journal with my research?

Check

Does the journal publish research you'd read?

Do you know what organization publishes the journal?

Can you contact the journal/publisher easily?

What are the editorial and peer review policies?

Do you know the editorial board members?

Are there clear article processing charges?

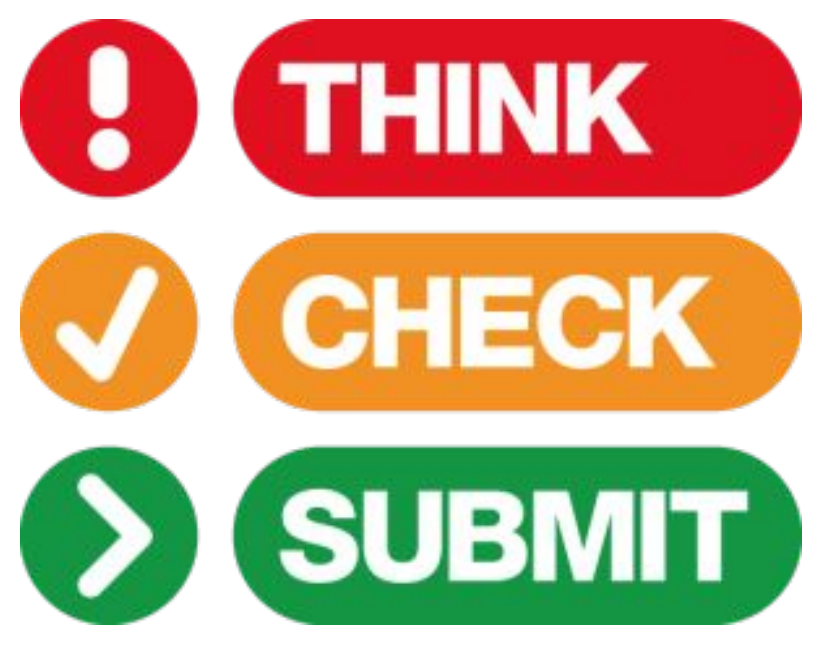

If you can answer yes, then submit!

thinkchecksubmit.org 


\section{Is this journal trustworthy?}

\section{Journal of Literature and Art Studies, USA}

DOI: $10.17265 / 2159-5836$

International Standard Serial Number: ISSN2159-5836 (Print), ISSN 2159-5844 (Online)

Co-editing with The Center of Chinese Literary Anthropology at SJTU

\section{Call for Papers and Book}

\section{Dear}

Greetings from Journal of Literature and Art Studies (ISSN: 2159-5836).

We have learned your abstract entitled CREATE A BOOK POWERS UP THE BRAIN from

46th Annual Conference of The Florida Foreign Language Association (FFLA 2015), October 15-17, 2015.

We would like to invite you to submit unpublished English papers, which are in areas included, but not limited to:

Literature studies, creative writing, Aesthetics Criticism, Feminist Literary Criticism, Poetics Criticism, Mythology studies, Romanticism, folklore, fine art, Animation studies, film studies, music studies, painting and calligraphy art etc.

If you are very interested in our journal and would like to join our reviewer team or editorial board group, please feel free to submit the papers or CV to us.

Doris Carly

Journal of Literature and Art Studies (ISSN 2159-5836)

Address: 616 Corporate Way, Suite 2-4876 Valley Cottage, NY 10989, USA

Email:literature.art@davidpublishing.com, literature.art@davidpublishing.org, art.literature@hotmail.com

Achievements

Journal of Literature and Art Studies (JLAS) has been indexed in Google Scholar, EBSCO, and CNKI, you can find some papers in the databases as following: 


\section{Look at the website}

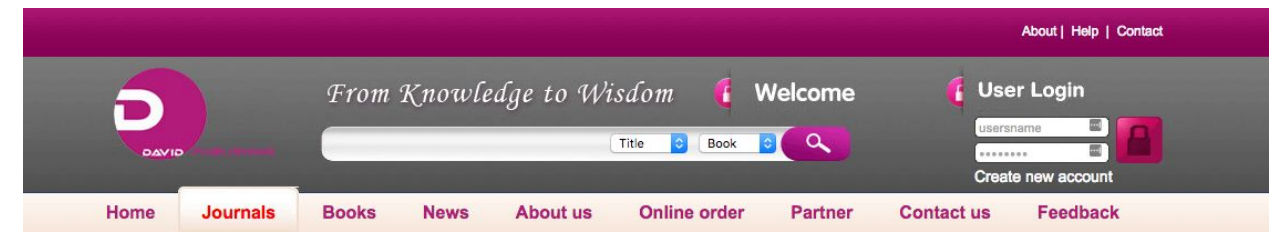

- Does it look professional?

- When was the last issue?

- Who are the editors?

- What about other journals?

- Check external links

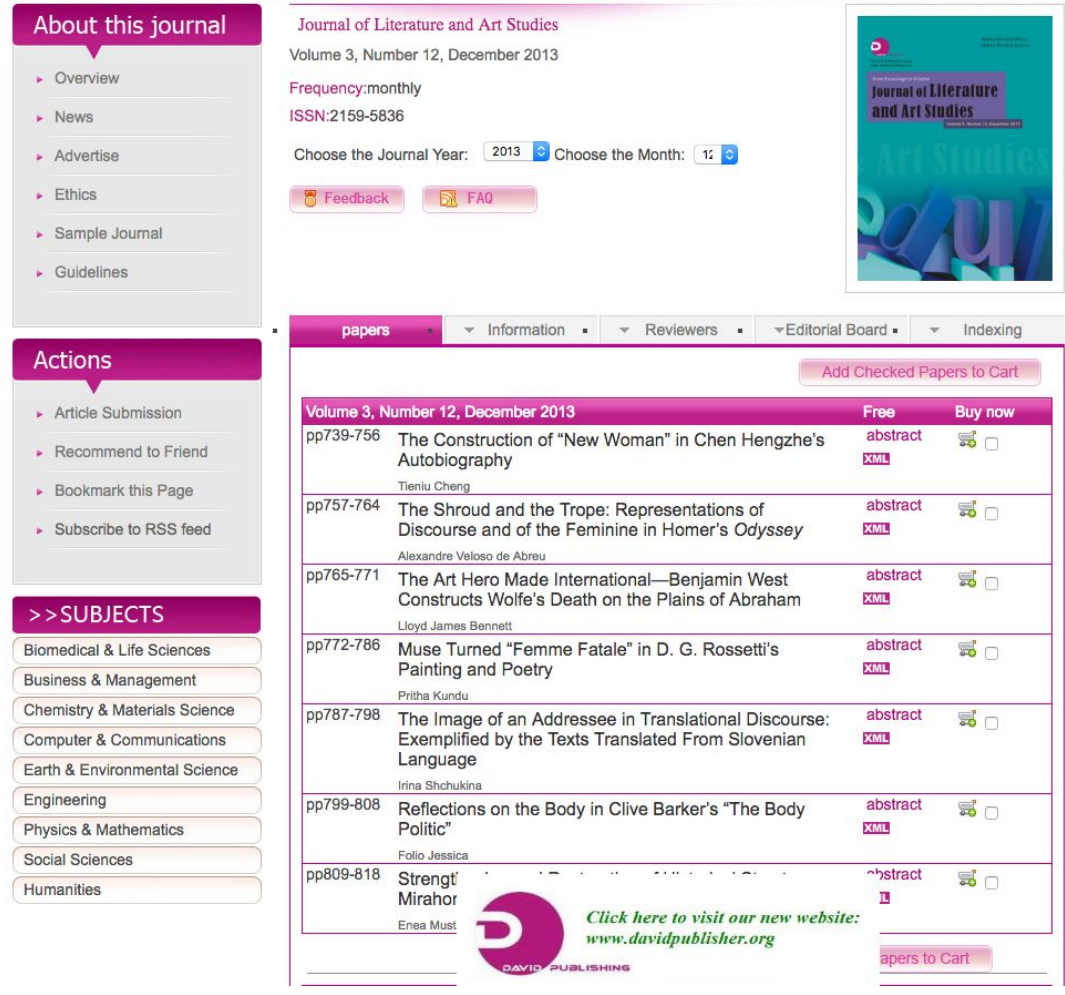




\section{Look at the contact page}

- What information is there?

- Does info 'add up'?

- Do you feel you can get help?

- Check any social media links

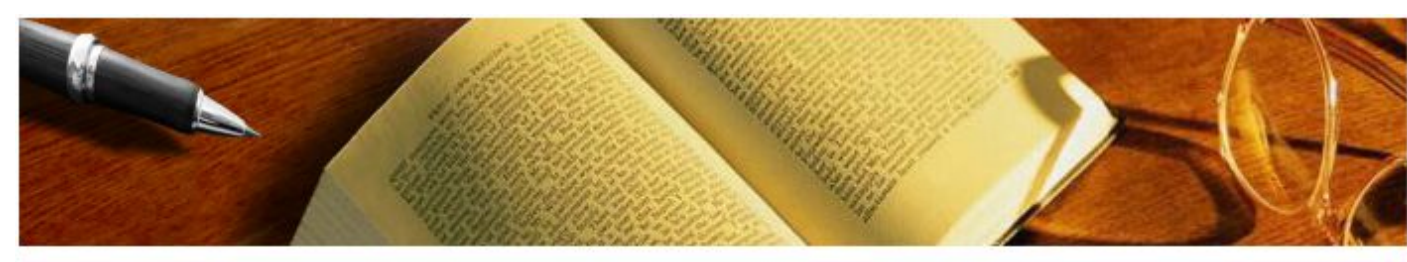

contact us

David Publishing Company, 616 Corporate Way, Suite 2-4876, Valley Cottage, NY 10989

Tel:1-323-984-7526; Fax:1-323-984-7374

Email: order@davidpublishing.com

www.davidpublisher.com

Pacific Time EST(eastern standard time) 


\section{Look at the contact page}

- What information is there?

- Does info 'add up'?

- Do you feel you can get help?

- Check any social media links

Inconsistent websites
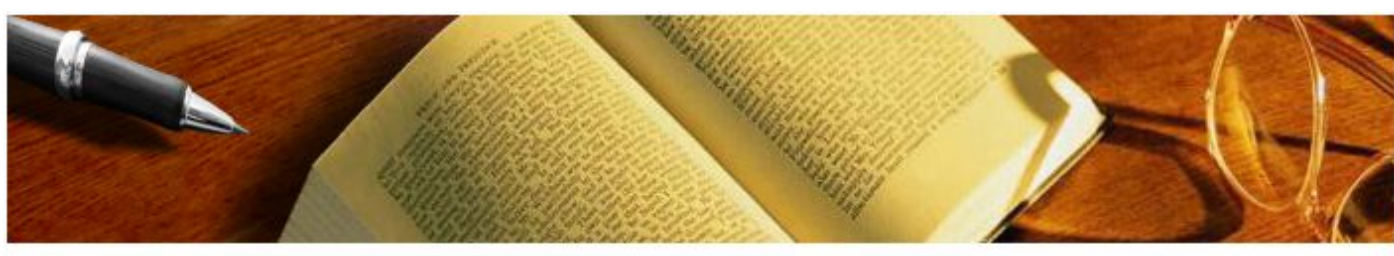

contact us

David Publishing Company, 616 Corporate Way, Suite 2-4876, Valley Cottage, NY 10989

Tel:1-323-984-7526; Fax:1-323-984-7374

Email: order@davidpublishing.com www.davidpublisher.com

Pacific Time EST(eastern standard time)

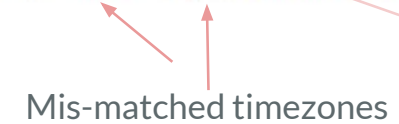

Focused on ordering
Mis-matched timezones
New York Office

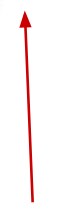

New York Office 


\section{Look for consistency}

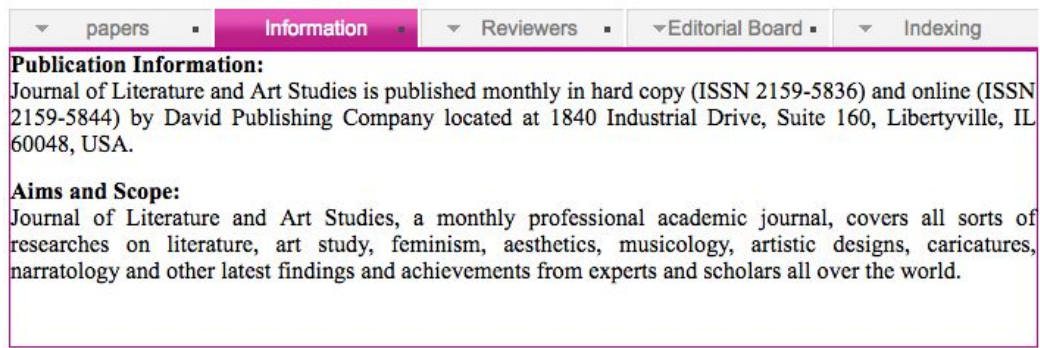

Journal of Literature and Art Studies

Volume 3, Number 12, December 2013

Frequency:monthly

ISSN:2159-5836

2011

Choose the Journal Year: $\begin{array}{r}2013 \\ \checkmark 2014\end{array}$ Choose the Month:

\section{F Feedback FAQ \\ 8 Feedback $F A Q$}

‥

Journal of Literature

and Art Studies

papers

Information

Reviewers

$\checkmark$ Editorial Board

Indexing

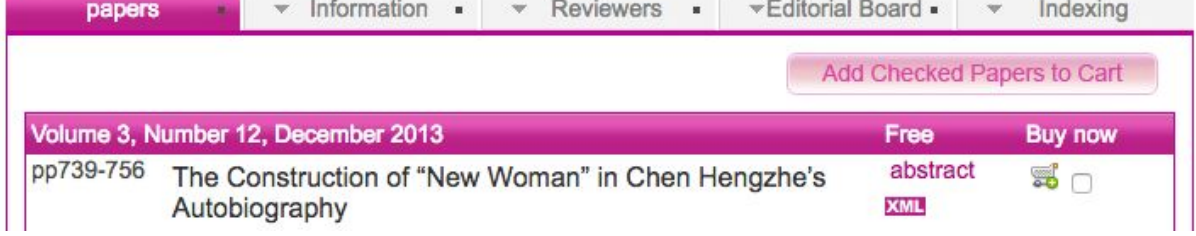




\section{Ask yourself,}

would I be proud to publish here? 


\section{What isn't a sign of an illegitimate journal}

- Non-US origin

- Rapid publication

- Mass emails

- Mega journal model

- Article Processing Charges

- But always double check DOAJ and OASPA before paying an APC! 
Rule of thumb:

Legitimate journals are more likely

to ask you to review than submit.*

*Except for special issues 


\section{Follow your gut instinct.}

No, really, trust yourself! 


\section{What have you heard about Open Access?}




\section{Open Access Concerns}

- Article Processing Charge (APC)

- Impact Factor

- Promotion

- Is it quality?

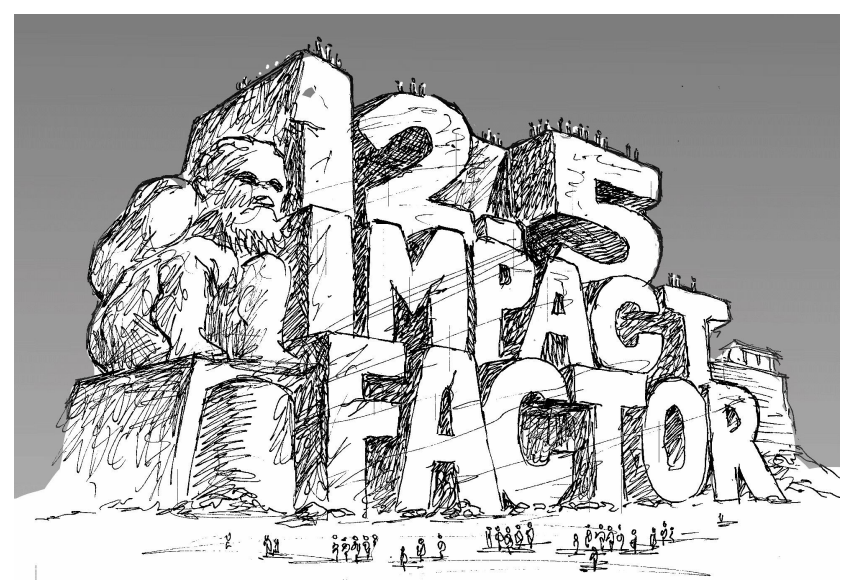


Myth \#1

Publishing Open Access is the only Open Access 
OA Two Ways

Publish Open Access

or

Archive Your Research 
Myth \#2

You're paying to publish 


\section{It's a different funding model.}

Open Access is not vanity publishing.

Publishing costs.

The APC business model shifts the cost.

Rather than subscriptions that only give access

to the subscribe, Open Access gives access to all. 
Myth \#3

All Open Access journals charge fees 


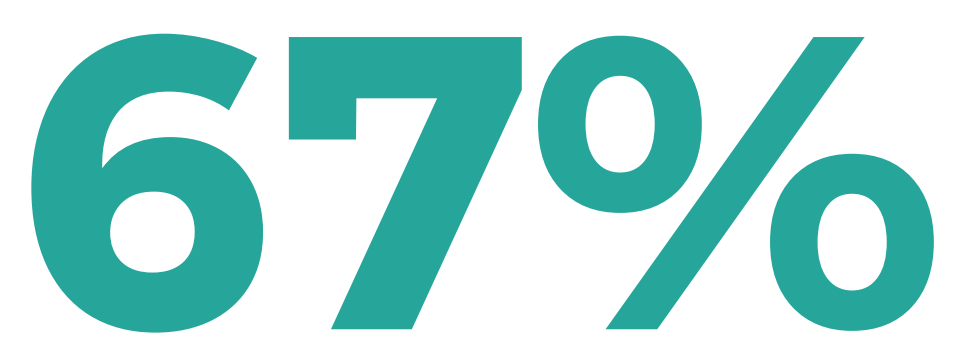

of Open Access journals lists in doaj.org do not have an APC 


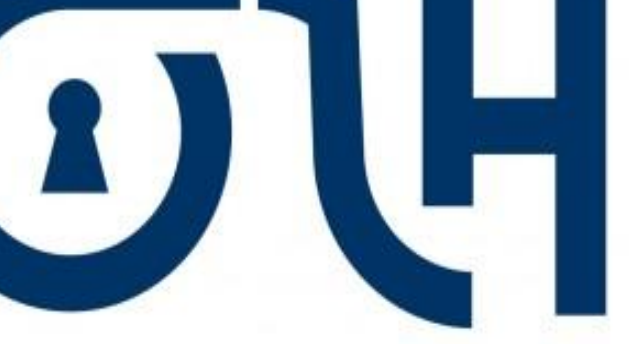

Open Library of Humanities openlibhums.org 
Myth \#4

Open Access journals are low in quality 
Open Access journals have the same standards of peer review, copyright, quality, prestige, and research impact. 


\section{Finding a suitable Open Access journal}

1. Browse the Directory of Open Access Journals

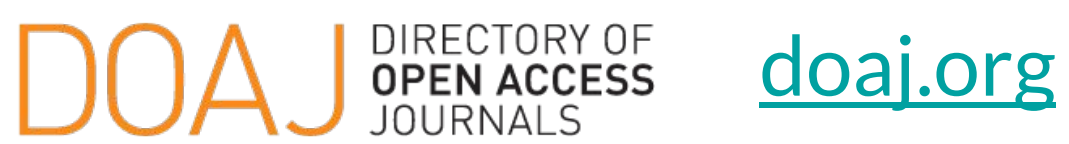

2. Use the Cofactor Journal Selection Tool

Cofactor cofactorscience.com/journal-selector

3. Ask mentors, colleagues, and librarians 


\section{- Journals vs Articles}

Journals $x$

\section{+ Subject}

- Article processing charges (APCs) What do these figures mean?

\begin{tabular}{|l|l|l|}
\hline 10 & count $\downarrow$ & $O R$ \\
\hline
\end{tabular}

Yes (4)

No Information (3)

No (1)

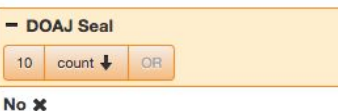

No $x$

+ Journal license

+ Publisher

- Country of publisher

\begin{tabular}{l|l|l|}
\hline 10 & count $\downarrow$ OR \\
\hline
\end{tabular}

United States $\mathbf{x}$

+ Full Text language

+ Peer review

+ Date added to DOA

Journals vs Articles: Journals $x$ Country of publisher: United States $x$ DOAJ Seal: No $x$

\section{$1-8$ of 8}

E] Global Journal of Geriatrics Nursing

http://journal.newcenturyscience.com/index.php/gign

APC: 160USD

Subject: Medicine: Nursing | Medicine: Internal medicine: Special situations and conditions: Geriatrics

Date added to DOAJ: 29 Oct 2014

E. SAGE Open Medical Case Reports

ISSN: 2050-313X (Online)

Blind peer review

(a) Br.NC

Subject: Medicine: Medicine (General)

Date added to DOAJ: 28 May 2014

E] Global Journal of Nursing Research

ISSN: 2309-2963 (Print); 2375-4664 (Online)

http://journal.newcenturyscience.com/index.php/gin

Subblect: Medicine: Nursing

Subject: Medicine. Nursing

ש. Online Journal of Nursing Informatics

ISSN: 1089-9758 (Print)

http://www.himss.org/ojn

Subject: Medicine: Nursing

Date added to DOAJ: 15 Oct 2003

E. Administrative Issues Journal

ISSN: 2153-7615 (Print)

http://www.swosu.edu/academics/aij/index.as

dministration (General)

Elobal Qualitative Nursing Research

SSN: 2333-3936 (Online)

Double blind peer review

Subject: Medicine: Nursing 
Yeah, but what about "predatory publishers"? 


\title{
Evaluate all journals.
}

\author{
Be critical.
}

Trust yourself.

And ask for help when you need it! 